\title{
Aerosol climatology over Nile Delta based on MODIS, MISR and OMI satellite data
}

\author{
H. S. Marey ${ }^{1,5}$, J. C. Gille ${ }^{1}$, H. M. El-Askary ${ }^{2,3,4}$, E. A. Shalaby ${ }^{5}$, and M. E. El-Raey ${ }^{5}$ \\ ${ }^{1}$ National Center for Atmospheric Research (NCAR), Boulder, CO, USA \\ ${ }^{2}$ Department of Environmental Sciences, Faculty of Science, Alexandria University, Moharem Bek, Alexandria, 21522, Egypt \\ ${ }^{3}$ School of Earth and Environmental Sciences, Schmid College of Science, Chapman University, Orange, CA, USA \\ ${ }^{4}$ Center of Excellence in Earth Observing, Chapman University, Orange, CA 92866, USA \\ ${ }^{5}$ Institute of Graduate Studies and Research (IGSR), Alexandria University, Egypt
}

Received: 9 March 2011 - Published in Atmos. Chem. Phys. Discuss.: 4 April 2011

Revised: 24 September 2011 - Accepted: 10 October 2011 - Published: 27 October 2011

\begin{abstract}
Since 1999 Cairo and the Nile delta region have suffered from air pollution episodes called the "black cloud" during the fall season. These have been attributed to either burning of agriculture waste or long-range transport of desert dust. Here we present a detailed analysis of the optical and microphysical aerosol properties, based on satellite data. Monthly mean values of Moderate Resolution Imaging Spectroradiometer (MODIS) aerosol optical depth (AOD) at $550 \mathrm{~nm}$ were examined for the $10 \mathrm{yr}$ period from 2000-2009. Significant monthly variability is observed in the AOD with maxima in April or May $(\sim 0.5)$ and October $(\sim 0.45)$, and a minimum in December and January $(\sim 0.2)$. Monthly mean values of UV Aerosol Index (UVAI) retrieved by the Ozone Monitoring Instrument (OMI) for $4 \mathrm{yr}$ (2005-2008) exhibit the same AOD pattern. The carbonaceous aerosols during the black cloud periods are confined to the planetary boundary layer (PBL), while dust aerosols exist over a wider range of altitudes, as shown by Cloud-Aerosol Lidar and Infrared Pathfinder Satellite Observation (CALIPSO) aerosol profiles. The monthly climatology of Multi-angle Imaging SpectroRadiometer (MISR) data show that the aerosols during the black cloud periods are spherical with a higher percentage of small and medium size particles, whereas the spring aerosols are mostly large non-spherical particles. All of the results show that the air quality in Cairo and the Nile delta region is subject to a complex mixture of air pollution types, especially in the fall season, when biomass burning contributes to a background of urban pollution and desert dust.
\end{abstract}

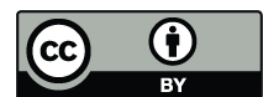

Correspondence to: H. S. Marey (hebasaid@ucar.edu)

\section{Introduction}

The characterization of aerosol optical and microphysical properties is crucial to the understanding of their effect on the Earth-atmosphere radiation budget and its climate (e.g. Haywood et al., 1999; Horvath et al., 2002; Meloni et al., 2005; Moorthy et al., 2009). Thus it is necessary that we continue to improve our characterization of aerosols, particularly in highly populated regions where the impact of aerosols on human health can be great (Hossny et al., 2001; Borai and Soliman, 2001; Heinrich and Slama, 2007). The Nile Delta, including Cairo, in Egypt is a region in need of better characterization of its atmospheric aerosol properties because of the area's high aerosol loading and lack of in situ observations. Figure 1 represents a base map of Egypt including its main cities highlighting the high population over the Delta region. Greater Cairo with a population of 16250000 in 2006 (DWUA, 2011), is one of the most polluted cities in the world. Particulate pollution is a serious problem (Nasralla et al., 1994), since traffic and industries located within the city of Cairo or in the neighboring regions emit particles all year long (Abu-Allaban et al., 2007). El-Metwally et al. (2008) and El-Askary et al. (2009) found that Cairo's and Alexandria's aerosol includes; "background pollution", "pollutionlike", and "dust-like" components. Moreover, Cairo is also bounded by the Mokattam Hills that produce large concentrations of airborne sand during strong spring wind events (Zakey et al., 2004). Favez et al. (2008) analyzed the chemical composition of bulk aerosols over 1.5-3 yr at two urban sites in Cairo. Their analysis indicated very high levels of mineral dust (over $100 \mu \mathrm{g} \mathrm{m}^{-3}$ ) in winter and spring; and more than $50 \mu \mathrm{g} \mathrm{m}^{-3}$ in summer and autumn. There are also seasonal sources of particulates, one of which is natural dust storms (Barnaba et al., 2004), that occur mainly in the spring and are called "Khamsin".

Published by Copernicus Publications on behalf of the European Geosciences Union. 


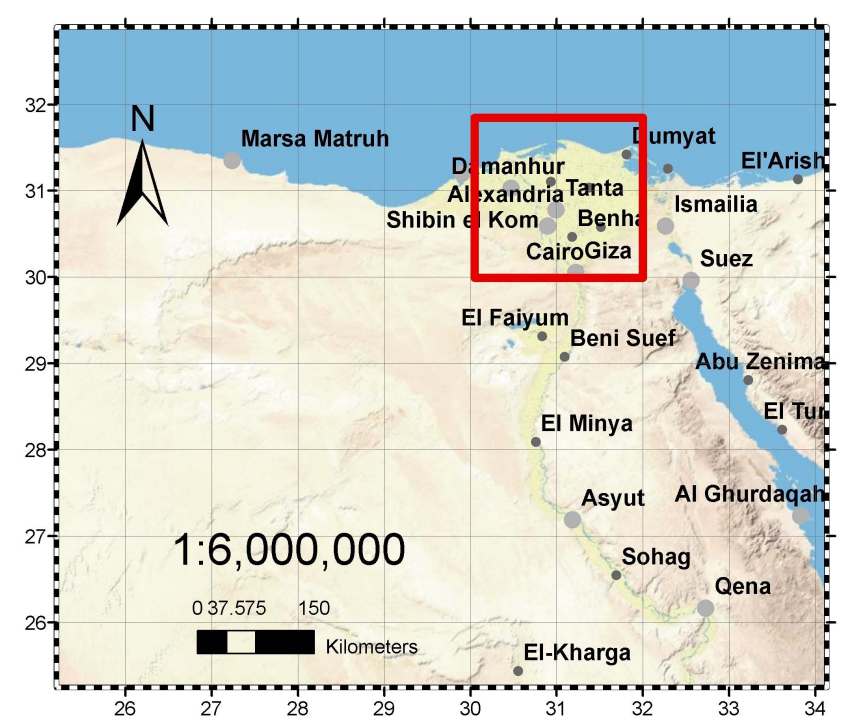

Fig. 1. Map of Egypt combined with its main cities, the red square represents the Nile delta region.

Another seasonal air pollution episode that has been observed in the fall every year since 1999 is locally known as the "black cloud". The black cloud is a dark haze that envelops Greater Cairo and surrounding areas (El-Askary and and Kafatos, 2008; El-Metwally et al., 2008) during the fall months for varying number of days. The impact of this haze is significant; it has potentially harmful effects on peoples' health, especially for people with sensitive eyes and respiratory problems. Children's lungs become very susceptible to illness when inhaling such high aerosol loadings hence, longterm exposure to these hazes can lead to asthma (Fleishman, 2009). Cairo aerosols are reported to have significant impacts on the public health (Hossny et al., 2001; Borai and Soliman, 2001). Furthermore, the opaque particle cloud over Cairo and its neighboring regions may affect regional climate through the scattering or absorption of radiation (Haywood et al., 1999; Herman and Celarier, 1997; Robaa, 2004). It may even influence the growth of plants in the Nile Delta by altering the amount of radiation that is available for photosynthesis (El-Metwally et al., 2008). Furthermore, high aerosol loads are likely to influence the water cycle by suppressing precipitations (Rosenfeld, 2000). Hence, the elevated levels of particulate matter over Cairo, particularly during the black cloud events, are a cause of concern (El-Askary and Kafatos, 2008).

Several studies have been conducted to understand the main reasons for the increased pollution levels in Cairo using ground-based and satellite air quality data (Zakey et al., 2004; Abu-Allaban et al., 2002, 2007; Alfaro and Wahab, 2006; El-Askary and Kafatos, 2008; Favez et al., 2008; Mahmoud et al., 2008; and El-Metwally et al., 2008; Marey et al., 2010 and Prasad et al., 2010). However, the genesis of the fall episodes (the black cloud season) is still under discussion and needs more investigations like the present study. In order to acquire further synoptic information and visualization of the aerosol characteristics, it is useful to analyze satellite data as well, since these data provide horizontal and vertical covering with fairly high (e.g. daily and monthly) temporal resolution. Marey et al. (2010) utilized data from several satellite instruments to examine the most likely reasons for the black cloud formation over Cairo. They used Moderate Resolution Imaging Spectrometer (MODIS) and the Multiangle Imaging SpectroRadiometer (MISR) with meteorological data and trajectory analyses to determine the cause of these events. MODIS fire counts identify the aerosol source as the burning of agricultural waste after harvest season in the Nile Delta region. MISR data show that these fires create low altitude $(<500 \mathrm{~m})$ plumes of smoke that flow over Cairo in a few hours, as confirmed by Hybrid Single-Particle Lagrangian Integrated Trajectory (HYSPLIT) forward trajectory analyses. Favez et al. (2008) analyzed the chemical composition during fall (i.e. the time of the black cloud) of bulk aerosols over 1.5-3 yr at two urban sites in Cairo. These analyses indicated that emissions of rice straw burning account for $50 \%$ of the water soluble organic carbon (WSOC). However, Prasad et al. (2010) suggest a different reason for the fall pollution (black cloud season). They showed that long range transport of dust at high altitude $(2.5-6 \mathrm{~km})$ from the Western Sahara and its deposition over the Nile Delta region is the major contributor to air pollution episodes at this season. Besides Zakey et al. (2004) mentioned the significant consequence of sand and dust particles emitted from the desert, and also from road-dust sand emitted from the road inside the towns itself in raising the aerosol optical levels in spring and fall. From above it is clear that this region experience a mixed aerosol loading scenarios hence, microphysical aerosol properties identification become highly needed.

In this paper we will present a detailed climatological analysis of the optical and microphysical aerosol properties over the Nile Delta region. Here we provide additional information on the different air pollution types that affect air quality over the study area, especially at the time of significant air pollution episodes, as well as the aerosol optical and physical characteristics. The paper is organized as follows: Sect. 2 briefly describes the data sets and tools used in this study. Section 3 is the analysis of the results, subdivided into three parts. The first part analyzes the aerosol optical depth climatology, the second discusses the absorption aerosol characteristics and the third part targets the aerosol microphysical properties. Section 4 presents a thorough discussion and concluding points.

\section{Data}

Several satellite sensors are used in this study coupled with AErosol RObotic NETwork (AERONET) ground measurement data. We used MODIS and Ozone Monitoring 
Instrument (OMI) data to study the aerosol optical properties, and the Multi-angle Imaging SpectroRadiometer (MISR) to examine the microphysical properties of the atmospheric aerosols, such as their size and shape. In addition, CloudAerosol Lidar and Infrared Pathfinder Satellite Observation (CALIPSO) data is utilized to acquire the vertical profile of the atmospheric aerosols. All satellite data used for this study were obtained from the Atmospheric Data Center of the NASA Langley Research Center (LARC) (http://eosweb. larc.nasa.gov/).

\subsection{Satellite data sets}

\subsubsection{MODIS}

MODIS instruments are onboard the NASA EOS (Earth Observing System) Terra (10:30 a.m. ECT, descending) and Aqua (01:30 p.m. ECT, ascending) satellites (Salomonson et al., 1989; Barnes et al., 1998). These instruments have high spatial resolution (10 km resolution) and a near-daily global coverage. Aerosol properties are retrieved over both land (Kaufman et al., 1997a, b) and ocean (Tanré et al., 1997) using seven well-calibrated spectral channels $(0.47-2.1 \mu \mathrm{m})$. The MODIS instruments aboard the Terra and Aqua satellites provide aerosol related parameters for the entire globe from 2000 and 2002, respectively. The MODIS operational Collection 5 algorithm from Terra and Aqua provides information about the global distribution of aerosols, but not over bright surfaces such as deserts. The reported uncertainty over non bright targets is $0.05 \pm 0.15 \tau$ ( $\tau$ is the aerosol optical depth) (Remer et al., 2005). We use the Deep Blue product over the desert region rather than the standard AOD product because the latter is retrieved using the dark-target approach (Kaufman et al., 1997a) at near-infrared wavelengths (2.1 and $3.8 \mu \mathrm{m}$ ) (Kaufman et al., 1997b). The Deep Blue algorithm has larger sensitivity to aerosols over bright surfaces because it employs two blue channels $(0.412$ and $0.470 \mu \mathrm{m})$, for which surface reflectances are relatively small, to infer aerosol properties (Hsu et al., 2004). The MODIS Deep Blue algorithm primarily uses the UV channels to provide aerosol retrievals over deserts and other areas where the operational algorithm cannot. The uncertainties of the deep blue product are reported to be around 25-30\% (Hsu et al., 2006). The MOD08 AOD data products from Terra, Aqua and Aqua deep blue AOD (Level 3, Collection 5) at 1 degree spatial resolution are utilized in this study. Further details of the development of the aerosol retrieval algorithm over land are discussed by Remer et al. (2006).

\subsubsection{CALIPSO}

CALIPSO was launched on 28 April 2006 as part of the NASA Afternoon Constellation (A-Train) (Stephens et al., 2002). It is the first lidar satellite to measure aerosol and cloud properties. More details about the aerosol algorithm are described by Winker et al. (2006). CALIPSO profiles range from the surface to $40 \mathrm{~km}$ (Winker et al., 2004) with a $333 \mathrm{~m}$ horizontal resolution and 30-60 m vertical resolution (Liu et al., 2004). CALIPSO has the capability to detect optical depths of 0.01 or less, so it can observe weak aerosol layers and thin clouds (McGill et al., 2007). Detailed descriptions are available at http://www-calipso.larc.nasa.gov/ and references therein. In this study we use Level 1B data. Since the original lidar backscatter data are rather noisy and require significant averaging for a proper identification of aerosol layers (Labonne et al., 2007), we perform a $5 \mathrm{~km}$ horizontal averaging to the data.

\subsubsection{OMI}

OMI was launched in July 2004 on NASA's EOS-Aura satellite, also part of the A-train constellation. In this study we analyze the OMI OMAERUVG (Torres et al., 2007) product to extract ultra-Violet Aerosol Index (UVAI) and aerosol absorption optical depth (AAOD) data. UVAI is a residual quantity that indicates the departure of the spectral dependence of the upwelling radiation from that of a pure Rayleigh atmosphere bounded by a Lambertian surface. Aerosol algorithms are described by Stammes and Noordhoek (2002) and Torres et al. $(2005$, 2007). Given the large size $(13 \times 24 \mathrm{~km}$ at nadir) of the OMI pixels, subpixel cloud contamination is a persistent problem resulting in the overestimation of the extinction optical depth and underestimation of the singlescattering co-albedo (Torres et al., 2007). However, in the calculation of the absorption optical depth, a partial cancellation of errors takes place that allows the AAOD retrieval even in the presence of small amounts of cloud contamination.

\subsubsection{MISR}

The MISR instrument on the Terra satellite acquires data with multiple angular views of the atmosphere and surface (Diner et al., 1998). These views are used to retrieve a number of physical aerosol parameters (Moroney et al., 2002; Muller et al., 2002; Martonchik et al., 2002) as well as aerosol microphysical properties (size and shape) (Martonchik et al., 2004). Further details about the aerosol algorithm and its retrieval can be found in Diner et al. (2001, 2008). MISR performs retrievals of the fraction of AOD due to "fine" (particle radii $<0.35 \mu \mathrm{m}$ ), "medium" (particle radii between 0.35 and $0.7 \mu \mathrm{m}$ ) and "large" (particle radii $>0.7 \mu \mathrm{m}$ ) particles as well as the fraction of AOD due to "spherical" and "nonspherical" particles from measurements in the four MISR spectral bands (Bull et al., 2008). Throughout this manuscript, the discussion of the relative size categories strictly corresponds to the ranges given above. Here, we have analyzed the latest version (Version 31) of the Level 3 monthly aerosol product of MISR from January 2001 to December 2008. 


\subsection{Ground air quality monitoring data or AERONET}

AERONET is a network of ground-based sun-photometers that measure atmospheric aerosol properties at several wavelengths. The aerosol particle size distribution and optical properties are derived by fitting measurements of the spectral AOD and sky radiances to radiative transfer calculations (Dubovik and King, 2000). For this study we use the Level 2 quality assured products (Holben et al., 1998) obtained by AERONET sunphotometer measurements performed in Cairo during the Cairo Aerosol CHaracterization Experiment (CACHE), which lasted from the end of October 2004 to the end of March 2006. Two Cairo stations are analyzed. The first station is the "Cairo_EMA" site at $30.08^{\circ} \mathrm{N}$ and $31.29^{\circ} \mathrm{E}$, where the a sun-photometer instrument is located at the EMA (Egyptian Meteorological Authority) in Cairo. The second station is at Cairo_University (Giza), (at $30.02^{\circ} \mathrm{N}$ and $31.2^{\circ} \mathrm{E}$ ). AOD data from October 2004 to April 2005 and from April 2005 to March 2006 from the Cairo University and Cairo EMA sites, respectively, are used for this study.

\subsection{Meteorological data and HYSPLIT trajectories}

The HYSPLIT (Hybrid Single-Particle Lagrangian Integrated Trajectory) model Version 4 was used to generate air mass backward trajectories. The HYSPLIT model is the latest version of an integrated system for computing air parcel trajectories, dispersion and deposition simulations (Draxler and Hess, 1997; Draxler et al., 2009). Data of mean monthly precipitation for the study period were taken from the National Oceanic and Atmospheric Administration (NOAA) Climate Data Assimilation System I, based on the National Centers for Environmental Prediction/National Center for Atmospheric Research (NCEP/NCAR) Reanalysis Project.

\section{Results}

\subsection{Aerosol optical depth (AOD) climatology}

We first investigate the AOD climatology as viewed by Terra and Aqua with MODIS Collection 5. Figure 2a shows the time series of monthly mean AOD at $550 \mathrm{~nm}$ from both Terra and Aqua over the Nile Delta region, which is defined as $30^{\circ} \mathrm{E}$ to $32^{\circ} \mathrm{E}$ and $30^{\circ} \mathrm{N}$ to $32^{\circ} \mathrm{N}$. The MODIS record length is different for Terra and Aqua: the monthly mean values from the Terra satellite are shown for the period February 2000-December 2009, and the Aqua values are from January 2003-December 2009. To compare the anthropogenic to natural air pollution sources, monthly time series of the Deep Blue Aqua $\mathrm{AOD}_{550}$ product over the Western desert $\left(25^{\circ} \mathrm{E}-29^{\circ} \mathrm{E}\right.$ and $\left.25^{\circ} \mathrm{N}-29^{\circ} \mathrm{N}\right)$ is depicted in Fig. $2 \mathrm{~b}$. We use the Deep Blue product over the desert region rather than the standard AOD product because the latter has larger sensitivity as discussed in Sect. 2. Both observations of AODs
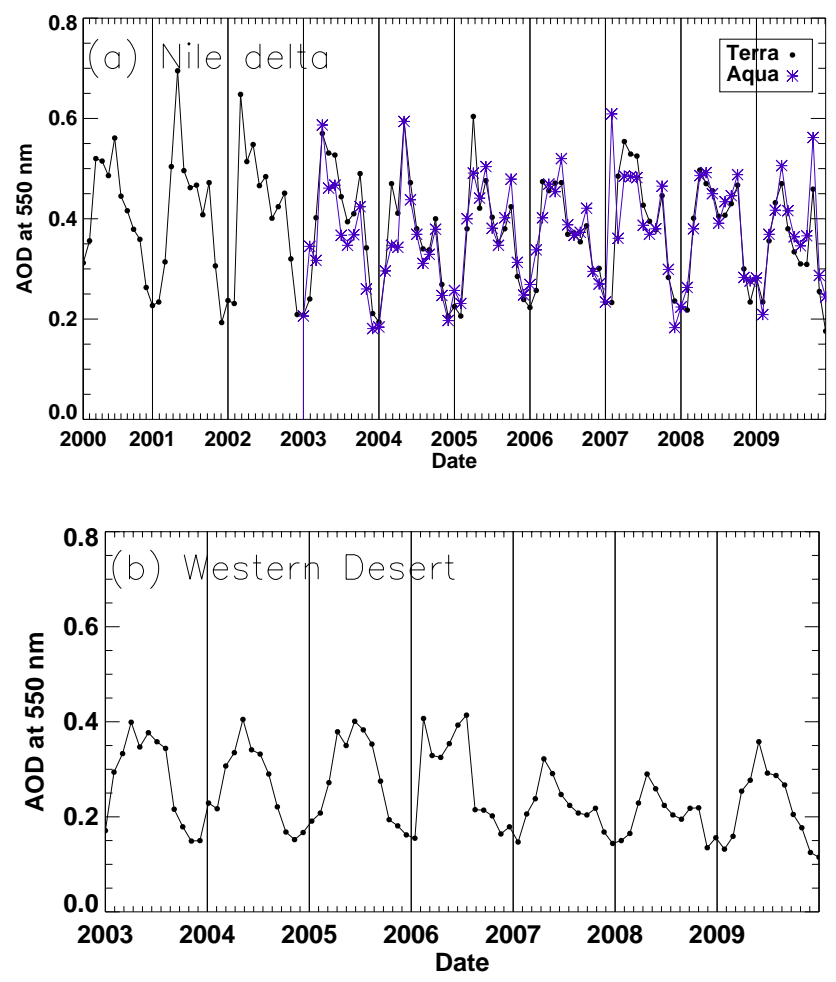

Fig. 2. (a) Time series plot of MODIS AOD at $550 \mathrm{~nm}$ over the Nile Delta from Terra and Aqua and (b) Western desert using Aqua deep blue data.

time series over the Nile Delta and the desert (Fig. 2a and b) exhibit annual and inter-annual variability, but with no obvious long term trend over the years. Table 1 indicates the annual average AOD with the associated standard errors for the study years over the Nile Delta and Western Desert regions. They show that there is no statistical significance of the discrepancies of the AOD means for both the Nile Delta and Western Desert regions. El-Metwally et al. (2010) argued the lack of interannual variation by the steadiness of the meteorological factors and human activities whose combination control the atmospheric concentration in particles over Cairo.

The Nile Delta $\mathrm{AOD}_{550}$ annual pattern is rather bimodal with two peaks; the first peak occurs during spring (around April, dust season), and secondary maximum occurs in October (time of black cloud events). The Deep Blue AOD 550 over the Western Desert of Cairo has a prominent maximum only during spring. Figure $3 \mathrm{a}$ and $\mathrm{b}$ present the climatological monthly means of MODIS standard $\mathrm{AOD}_{550}$ and Deep Blue $\mathrm{AOD}_{550}$ for the examined period over the Nile Delta and desert region, respectively. The standard errors of the monthly mean values are expressed with the vertical bars. The monthly climatological means of MODIS AOD 550 over the Nile Delta have a distinct annual cycle, with minima of $\sim 0.21 \pm 0.02$ in winters, and a maximum during the spring/fall peaks between $0.45 \pm 0.04,0.52 \pm 0.05$ and 
Table 1. Annual AOD means for both Terra and Aqua over Nile Delta and for Aqua Deep Blue over the Western Desert of Egypt.

\begin{tabular}{cccc}
\hline Year & $\begin{array}{c}\text { Annual mean of } \\
\text { Terra AOD over } \\
\text { Nile Delta }\end{array}$ & $\begin{array}{c}\text { Annual mean of } \\
\text { Aqua AOD over } \\
\text { Nile Delta }\end{array}$ & $\begin{array}{c}\text { Annual mean of } \\
\text { Aqua AOD over } \\
\text { Western Desert }\end{array}$ \\
\hline 2000 & $0.42 \pm 0.03$ & - & - \\
2001 & $0.4 \pm 0.05$ & - & - \\
2002 & $0.41 \pm 0.04$ & - & - \\
2003 & $0.4 \pm 0.04$ & $0.36 \pm 0.04$ & $0.28 \pm 0.04$ \\
2004 & $0.36 \pm 0.04$ & $0.34 \pm 0.03$ & $0.26 \pm 0.03$ \\
2005 & $0.37 \pm 0.04$ & $0.37 \pm 0.03$ & $0.28 \pm 0.03$ \\
2006 & $0.37 \pm 0.03$ & $0.38 \pm 0.03$ & $0.28 \pm 0.04$ \\
2007 & $0.39 \pm 0.04$ & $0.39 \pm 0.04$ & $0.22 \pm 0.02$ \\
2008 & $0.38 \pm 0.03$ & $0.38 \pm 0.03$ & $0.20 \pm 0.02$ \\
2009 & $0.33 \pm 0.03$ & $0.36 \pm 0.03$ & $0.22 \pm 0.03$ \\
\hline
\end{tabular}
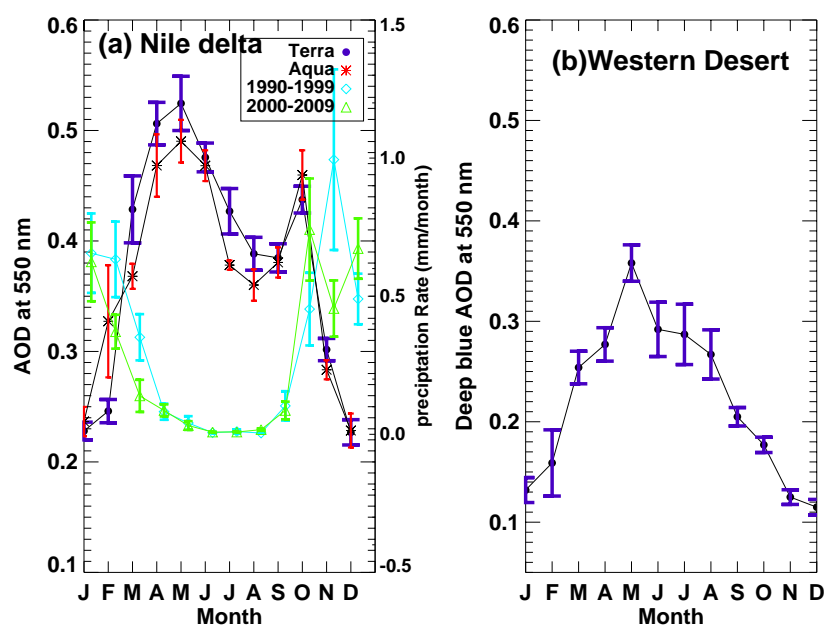

Fig. 3. (a) Climatology MODIS monthly AOD means over the Nile Delta from Terra (2000-2009) and Aqua (2003-2009), the right axis is for the precipitation rate of Nile Delta for 1990-1999 and 2000-2009. (b) Climatology MODIS monthly AOD means over the Western desert using Aqua deep blue (2003-2009) data product, the vertical bars represent the standard deviations.

$0.44 \pm 0.03,0.46 \pm 0.04$, from Terra and Aqua, respectively. The "background" AOD between the two observed maxima is probably associated with urban-industrial pollution typical of larger cities in developing countries (e.g. Dey and Di Girolamo, 2010; El-Metwally et al., 2010).

We performed an analysis to investigate the relationship between precipitation rate and AOD over the study region. It should be noted that despite the fact that the available precipitation data suffer from errors (e.g. Kistler et al., 2001), they can be used for long time averaging. The monthly climatology means of the precipitation rate over the Nile Delta for two $10 \mathrm{yr}$ periods, 1990-1999 and 2000-2009, are additionally plotted in Fig. 3a. They reveal a distinct minimum in the summer and a maximum in winter. The frequent occurrences of rain event in winter (which lead to high precipitation rate) decrease the airborne particles by washing them out and hence reduce the AODs to its minimum. Conversely, the AOD increases in summer because particle accumulation is favored in this season by the absence of precipitations. The photochemical processes in summer and the convections and thermal motions act at the same time (besides low precipitation rate) to slight increase the values of aerosol optical characteristics. The role of precipitation is less important in fall and spring where the precipitation rate and the AODs have no distinct correlation. Thus the role of emission sources is more crucial for the AOD variation at those seasons (fall and spring). Comparing these results to other studies over the Mediterranean basin, Papadimas et al. (2008) had shown that the precipitation rate is one of the strongest removal processes for atmospheric aerosols in winter. However, in the summer the emission rates of anthropogenic pollution are more important causes of the AOD variations.

Figure 3a displays higher AOD monthly means for Terra than Aqua in the spring and in the summer; however these differences are not statistically significant. This is consistent with Remer et al. (2008)'s result, where they showed that there were not significant differences between the Terra and Aqua products.

The monthly climatological means of $\mathrm{AOD}_{550}$ over the Western Desert (Fig. 3b) exhibit a minimum of $\sim 0.1 \pm 0.02$ in winter, and a maximum in spring of $\sim 0.35 \pm 0.03$. Hence, the monthly mean AOD values over the Nile Delta region are higher than those over the Western Desert. This is attributed to local air pollution sources that exist throughout the year over Nile Delta cities (e.g. Cairo) (Abu-Allaban et al., 2007).

AERONET ground-based measurements of AOD data are used for comparison with MODIS data. The calculation is done for the period October 2004-March 2006. Because the air pollution episodes (spring dust outbreaks and the October black cloud phenomenon) repeat each year, we assume that the AERONET data of 2004 and 2005 are considered to be representative of all years. Monthly variations of the AOD at $500 \mathrm{~nm}$ and $1020 \mathrm{~nm}$ for the period that starts in October 2004 and ends in April 2005 is presented in Fig. 4. The AERONET AOD observations at the same wavelength (500 and $1020 \mathrm{~nm}$ ) of the year that starts in April 2005 and ends in March 2006 are presented in Fig. 4. The vertical bars represent the standard errors. The observations from both years at $500 \mathrm{~nm}$ display maxima in April and October, with value of $\sim 0.4-0.55$ and a minimum value of $\sim 0.2-0.25$. The April monthly AERONET AOD (at Cairo) mean is $0.47 \pm 0.1$ compared to $\sim 0.6$ from Terra and to 0.5 from Aqua. The October AERONET AOD monthly mean is $0.48 \pm 0.075 \mathrm{com}$ pared to $\sim 0.43$ from Terra and 0.48 from Aqua. Accordingly, MODIS monthly AODs are in general agreement with AERONET AOD monthly data. The AOD at $500 \mathrm{~nm}$ is considerably higher than those values at $1020 \mathrm{~nm}$ in the summer and fall seasons. In the spring, the AOD wavelength 


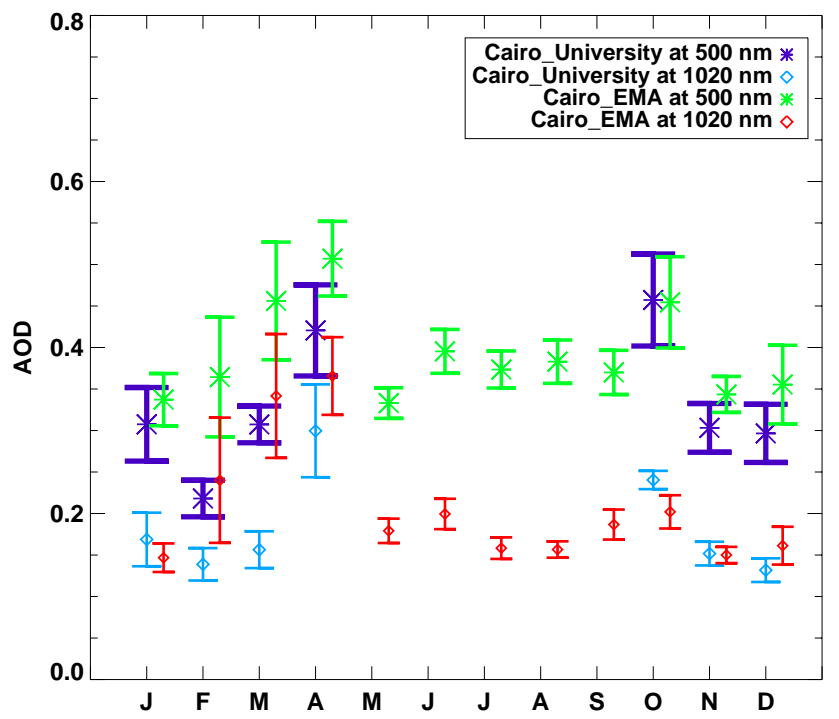

Fig. 4. AERONET AOD observations at 500 (purple) and 1020 (red) nm over Cairo for Cairo_University (from October 2004 to April 2005) and Cairo_EMA (from April 2005 to March 2006) stations. The vertical bars represent standard errors.

dependence is not significant since the associated standard deviations overlap. This wavelength dependence gives information about particle size which will be further discussed in Sect. 3.3.

\subsection{Absorption aerosol characteristics}

The UVAI is a product of the standard OMI aerosol retrieval which indicates the UV absorbing aerosols (Torres et al., 2007). Absorbing aerosols such as carbonaceous aerosols, desert dust, and volcanic ash above the boundary layer yield positive UVAI values $(>1)$, whereas non-absorbing small particle aerosols yield small negative values (Torres et al., 2007; Braak et al., 2007). Absorbing aerosols in the boundary layer may produce small UVAI values $(<0.5)$ that make it difficult to separate their signal from the background noise.

The daily OMI UVAI variations for 2005-2008 as well as its monthly climatology means of the four-year time period (2005-2008) are displayed in Fig. 5. It shows positive values all year long indicating the continual presence of absorbing aerosols (Torres et al., 1998). In addition, the daily UVAI time series of the four data sets (2005-2008) exhibit a large inter-annual variability. Sharp increases in the daily UVAI values are detected in the spring and the fall. The UVAI monthly climatology shows maxima of $1.2 \pm 0.18$ and $0.9 \pm 0.08$ in April and October. Since the large air pollution episodes occur during the spring and fall seasons, our discussion will focus on analyzing aerosol characteristics during those time periods. The high UVAI values in spring are consistent with the large AOD values observed in the MODIS data. These are most likely associated with Saharan dust
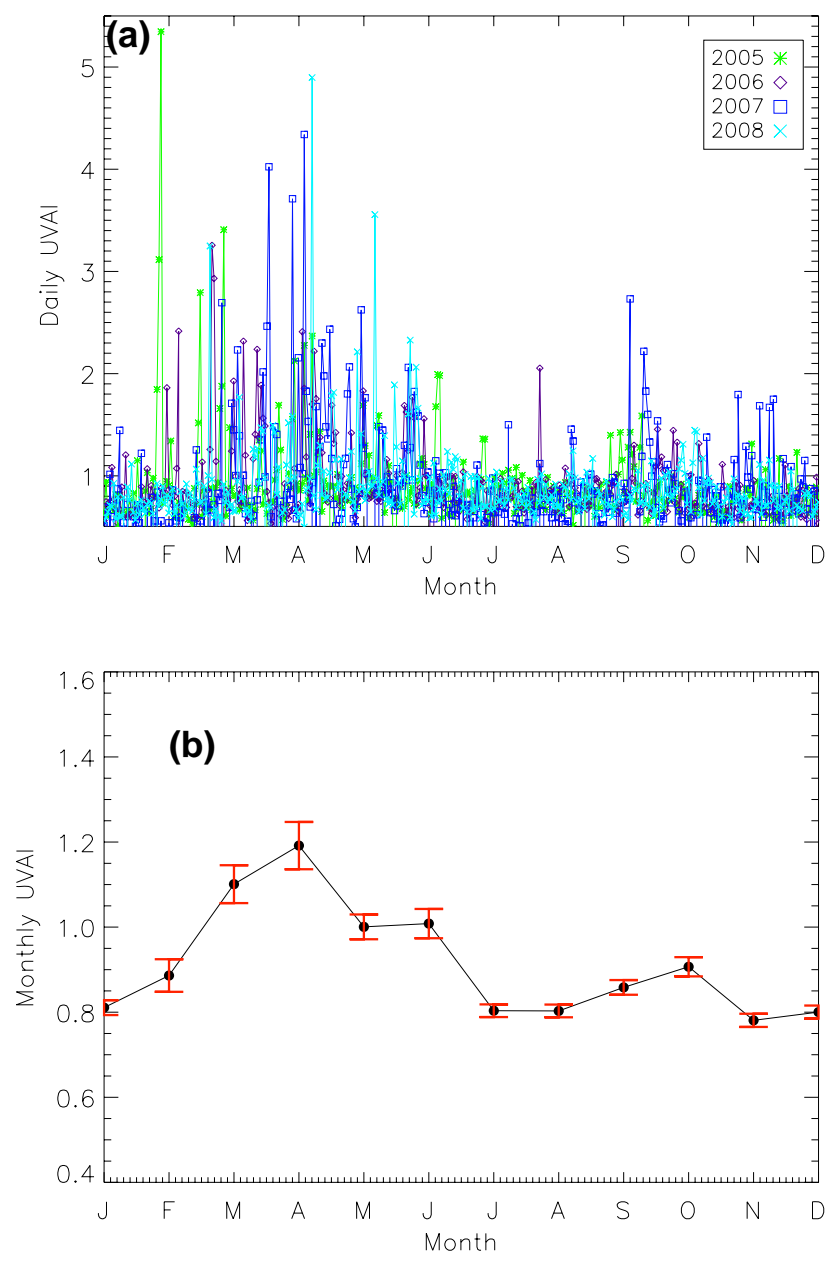

Fig. 5. (a) the monthly climatology means of UVAI over Nile Delta for four years (2005-2008) and (b) is Daily OMI UVAI for 20052008. The vertical bars represent standard errors.

aerosols transported into Cairo. Ahmad et al. (2006) showed that the monthly time series of UVAI over North Africa peaks from March to June as a result of mineral dust aerosols. It is assumed that these dust particles are lofted by the winds from arid and semi-arid areas, raising the AOD in spring over Egypt (Papadimas et al., 2008).

In spite of comparable AOD values in spring and October as indicated by MODIS, the UVAI is more enhanced in April than in October. This is consistent with the UVAI sensitivity to aerosol layer height (Torres et al., 1998), where the dust aerosols exist in a wider range of altitudes than the aerosols that exist during the black cloud time (October), which are confined to the planetary boundary layer (PBL) (Marey et al., 2010). The UVAI tends to be insensitive to the boundary layer aerosols (Mahowald and Dufresne, 2004). This is confirmed by the CALIPSO aerosol total backscattering profiles at $532 \mathrm{~nm}$ (Level 1 Version 2) (Winker et al., 2003). Figure 6a and b present CALIPSO lidar aerosol vertical profiles on 30 October 2007 and on 17 April 2007, 
representing the April and October episodes, respectively. The 30 October 2007 data display the orbit-altitude crosssection in the vicinity of Cairo $\left(30.03^{\circ} \mathrm{N}, 31.35^{\circ} \mathrm{E}\right)$, whereas the 17 April 2007 data are located east of Cairo. Figure 6a reveals strong total attenuated backscatter at $532 \mathrm{~nm}$ in two regions. One of them is close to the surface in the latitude range of 29 to $30.5^{\circ} \mathrm{N}$ at altitude less than $500 \mathrm{~m}$ which is indicated by the intense grey colors. The other aerosol layer is at top altitude of $1 \mathrm{~km}$ in the lat range of 26 to $28^{\circ} \mathrm{N}$ (south of Cairo) and it is indicated by the red colors. Figure $6 \mathrm{~b}$ exhibits strong back-scattering at wide range of altitudes, where the aerosol layer heights range from $2-5 \mathrm{~km}$. The MODIS true color image from both Terra and Aqua on 17 April 2007 (not shown) corroborates the existence of dust storms on that day. Thus there is a strong back-scattering at higher altitudes on 17 April than 30 October 2007.

Additionally, the variation in the magnitude of UVAI in April and October could arise from different aerosol types that exist and predominate at these times. Recent study by ElMetwally et al. (2011) of the radiation forcing in April and October over Cairo illustrated different contributions to the radiative forcing to the bottom and the top of the atmosphere (RFBOA, RFTOA). The April aerosols add 53\% and $66 \%$ to the RFBOA, and RFTOA, whereas the October aerosols increased RFBOA and RFTOA by approximately $30 \%$. This suggests the presence of different aerosol types in the two months, where the April is affected by desert dust and October by biomass burning pollution. To verify the aerosol types, the aerosol size and shape will be discussed in the following section.

\subsection{Aerosol microphysical properties (size and shape)}

The identification of the predominant particle size (i.e. small or large particles) over Cairo during the spring and fall seasons can be accomplished by examining the seasonality of the observed AERONET Angstrom Exponent (AE). Small AE values are associated with large dust particles, whereas large AE values reflect small size aerosols. This result can be corroborated by the monthly time series plot of AERONET-derived AE during the period April 2005March 2006 (Fig. 7) that shows that small AE values (presumably desert dust) dominate during spring, and larger $\mathrm{AE}$ values prevail during the rest of the year. These larger $\mathrm{AE}$ values are associated with the presence of small particles. Figure 8 is an example of the desert dust event that occurred on 17 April 2007 (Fig. 6a). It demonstrates the enhanced UVAI in North Africa and its long range transport to Egypt causing an air pollution episode at this time of the year. This atmospheric transport pattern is evaluated by examining 5 day back trajectories originating from Cairo on 17 April 2007 at 10:00 UTC. We computed the trajectories using the HYSPLIT model which was initiated at $3000 \mathrm{~m}$ and $4000 \mathrm{~m}$ a.g.l., as indicated by red and black colors in Fig. 8, respectively. Both backward trajectories suggest that the ori-
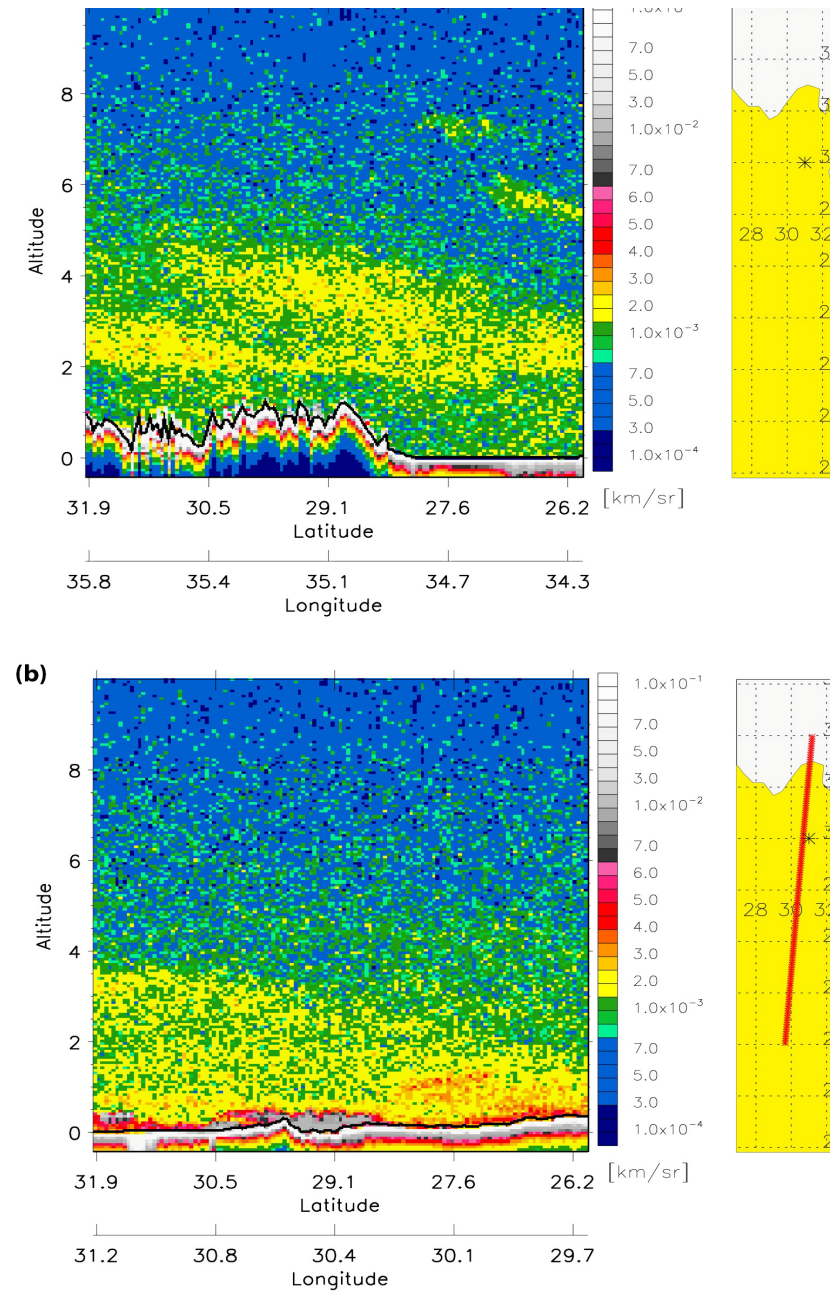

Fig. 6. CALIPSO total attenuated backscatter, (a) on 16 April 2007 at 23:31 UTC and (b) and on 30 October at 23:42 UTC. The black line represents the surface elevation. The yellow small map represents the location at the Nile Delta including Cairo and the red line represents the calypso path.

gin of the high UVAI over Cairo at this day is the air mass flowing from the west and south west directions. Past studies have indicated that the atmospheric transport of dust from North Africa is strongly affected by the North Atlantic Oscillation (NAO) (Moulin et al., 1998).

The monthly averaged AERONET AE data of 2005 gives us information about the aerosol size. It is supposed from $\mathrm{AE}$ values that the spring episodes are mainly dust particles, and this is corroborated by the OMI UVAI image of North Africa. We will investigate the aerosol size and shape in more detail using MISR Level 3 monthly AOD fractions from 2001-2008. These data can provide more information about the aerosol size and shapes, especially during air pollution episodes. Thus we have a long time series that can give us information about the aerosol microphysical properties. 


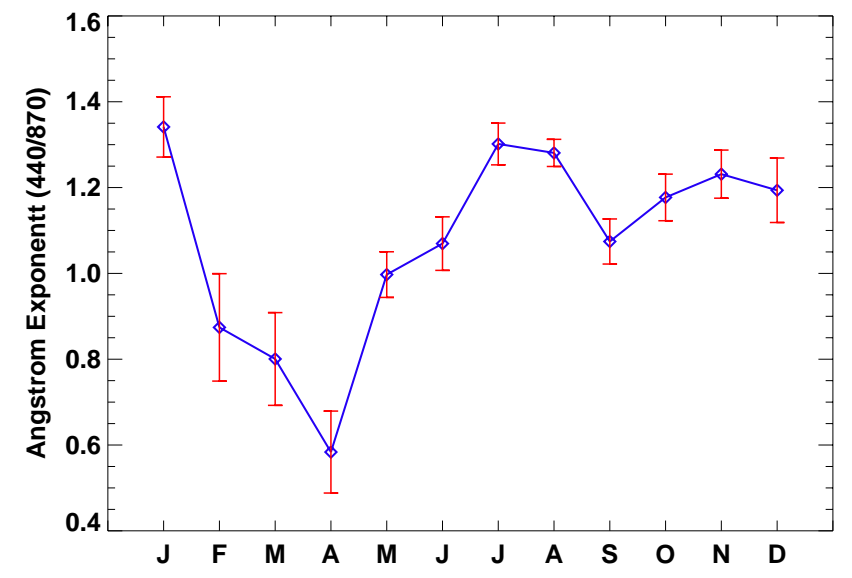

Fig. 7. AERONET AE observations over Cairo from April 2005 to March 2006. The vertical bars represent standard errors.

The MISR AOD at $558 \mathrm{~nm}$ is subsetted to small, medium, and large size particles and to spherical and non-spherical particles. A monthly climatology of AOD fractions, by size and shape, over the Nile Delta is calculated for eight years (2001-2008) and presented in Fig. 9a and b. It is worth noting that the non-spherical particles are significantly higher in the spring than the rest of the year (Fig. 9a), which is consistent with the dust source (Marey et al., 2010). The AOD of non-spherical particles reaches a maximum in April with a value of $\sim 0.3 \pm 0.09$. The maximum of the spherical fraction AOD occurs in October $(\sim 0.95 \pm 0.02)$. The small AOD fractions are significantly higher in summer as well as in October. During the black cloud season (October), the AOD of the small particle is highest, followed by large particle AOD, and then the medium particle AOD fractions. In April the AOD proportion is higher for large size, followed by small, then medium sizes as illustrated in Table 2. To further evaluate the MISR results, we examine monthly size distributions from the AERONET Cairo stations. Figure 9c demonstrates the monthly size distributions for October and April of 2005. It reveals that the aerosol size distribution in April has a single peak at sizes larger than $1 \mu \mathrm{m}$, so the dominant particles are the large aerosols. In contrast the October size distribution displays a bimodal pattern which peaks at $\sim 0.1$ and $\sim 2 \mu \mathrm{m}$. Therefore we can conclude that October exhibit both sizes, small and large particles with more than $95 \%$ spherical particles, whereas the dominant particles in April are large non-spherical particles. This results agrees with Prasad et al. (2010) proposing a mixed aerosol scenario during the black cloud season.

\section{Discussion and conclusion}

We have presented extensive satellite-based climatology of aerosol optical and microphysical properties over the Nile
Table 2. MISR AOD monthly mean size fractions for October and April over the period of 2001-2008.

\begin{tabular}{clll}
\hline & $\begin{array}{l}\text { MISR AOD } \\
\text { of the small } \\
\text { particle fraction }\end{array}$ & $\begin{array}{l}\text { MISR AOD } \\
\text { of the medium } \\
\text { particle fraction }\end{array}$ & $\begin{array}{l}\text { MISR AOD } \\
\text { of the large } \\
\text { particle fraction }\end{array}$ \\
\hline October & $0.46 \pm 0.03$ & $0.15 \pm 0.02$ & $0.37 \pm 0.04$ \\
April & $0.38 \pm 0.044$ & $0.2 \pm 0.038$ & $0.4 \pm 0.037$ \\
\hline
\end{tabular}

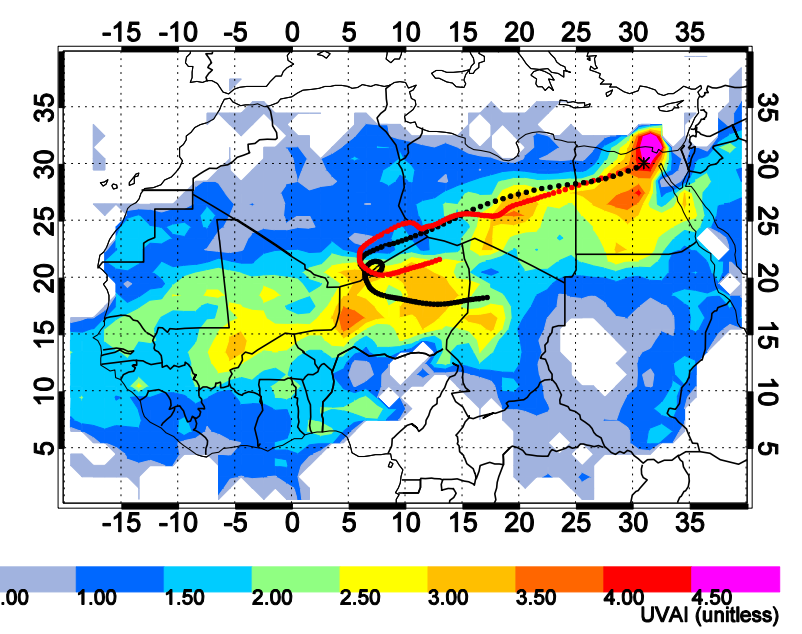

Fig. 8. OMI UVAI image over North Africa on 17 April 2007. The dotted lines are the HYSPLIT backward trajectories starting from Cairo on 17 April 2007 10:00 UTC for 5 days, the red trajectory starts at height of $3000 \mathrm{~m}$ a.g.l. and the black trajectory starts at height of $4000 \mathrm{~m}$ a.g.l.

Delta, especially during the time of air pollution episodes either of natural (dust) or anthropogenic (black cloud) origins namely, April and October. To derive AOD climatology the MODIS Collection 5 monthly AOD $_{550}$ product derived for $10 \mathrm{yr}$ from Terra data and for $7 \mathrm{yr}$ from Aqua data has been employed. Additionally, an OMI UVAI for 4 yr (2005-2008) is used for the climatology of aerosol absorption. MISR AOD fractions at $558 \mathrm{~nm}$ are used to study the climatology of microphysical properties as size (small, medium and large) and shape (spherical and non-spherical). To further understand the results, the available AERONET aerosol data for 2004 and 2005 have been analyzed.

The monthly variability of aerosol properties over the Nile Delta reveals that $\mathrm{AOD}_{550}$ peaks during April $(\sim 0.5)$ and October $(\sim 0.45)$, which is to be expected since these are the times when the dust and black cloud events occur in the region. However, the deep blue $\mathrm{AOD}_{550}$ mean values over the Western desert exhibit maxima only in the spring, with a mean value $\sim 0.35$, that results from the enhanced emission of natural aerosols (dust storms). The difference between 

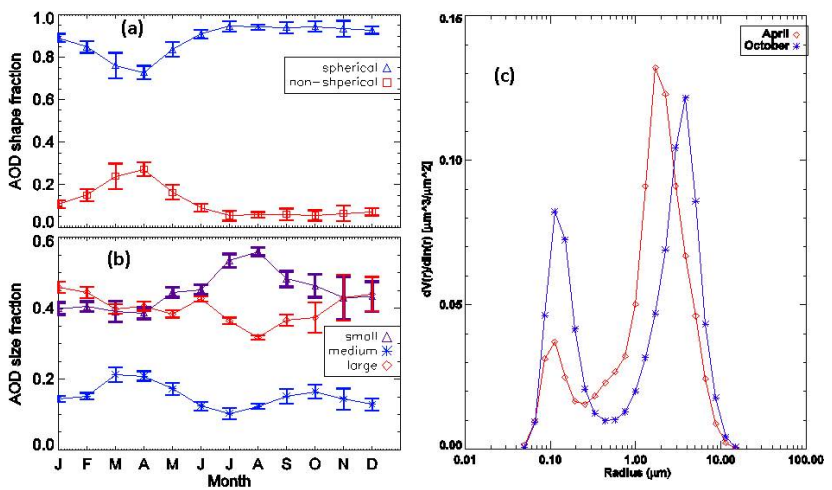

Fig. 9. (a) Climatology of AOD shape fractions from MISR (20012008) at $558 \mathrm{~nm}$ (green band) over Nile Delta and (b) AOD size aerosol fractions at $558 \mathrm{~nm}$ (green band) over the Nile Delta for eight years (2001-2008). (c) is size distribution of AERONET station at Cairo on April 2005 (red color), and October 2005 (blue color).

the spring AOD over the Nile Delta and the Western desert suggests additional aerosol loading in the Nile Delta due to anthropogenic sources. Moreover, the "background" AOD between the two observed maxima (April and October) is probably associated with urban-industrial pollution typical of larger cities (e.g. India cities, Cairo) in developing countries (Abu-Allaban et al., 2002, 2007; Alfaro and Wahab et al., 2006; Dey and Di Girolamo, 2010). The time series of Terra and Aqua MODIS AOD 550 exhibits year to year variability over the Nile Delta and Western desert. No yearly trend is observed.

The monthly AOD means are anticorrelated with the monthly precipitation. Consequently precipitation is an important factor in atmospheric removal processes of aerosols in winter, and in the accumulation of particles during summer. However in the spring and fall, the emission sources have more influence on regulating the aerosol levels, since the AOD anticorrelation to the precipitation at these seasons is poor. The monthly $\mathrm{AOD}_{500}$ from AERONET stations over Cairo agree with MODIS results, even though the observational methodology and time periods are not coincident. OMI monthly mean values of UVAI for $4 \mathrm{yr}$ (2005-2008) indicate that, the absorbing aerosols exist all year long. This may be attributed to dust, (Favez et al., 2008) and anthropogenic emissions present all year. These findings agree with past studies such as Favez et al. (2008), where their study showed high background concentration of dust aerosol levels $\left(50 \mu \mathrm{g} \mathrm{m}^{-3}\right)$ all year long. Zakey et al. (2004) highlighted the role of sand and dust particles in increasing the aerosol optical properties in the transitional seasons (spring and autumn) during strong wind events. They also comment that the Mokatem Hills that surround Cairo are an important source of fine sand. El-Askary and Kafatos (2008) indicated that the topography of the Delta region is an important contributor in the stagnant atmosphere and the presence of the prolonged pollution episodes.

The dust aerosols are observed both within and above the planetary boundary layer (PBL), whereas the aerosols at the time of the black cloud event are confined to the PBL (Marey et al., 2010). Therefore, it is expected that there will be lower UVAI values than those found in April. In general, the daily and monthly means of UVAI indicate that both air pollution episodes (spring and fall) have absorbing features. This implies that the air pollution episodes have dust or carbonaceous particles. In order to distinguish whether the predominant aerosol type is smoke or dust, the monthly climatology of MISR size- and shape-segregated aerosol AOD are analyzed. They show that the aerosols in October (time of black cloud) are spherical with higher percentage of small and medium aerosol size fractions, whereas the spring aerosols are mostly large non-spherical particles. The AERONET size distribution and $\mathrm{AE}$ data also show the abundance of large particles during April, with more small particles during the rest of the year. Thus, this result indicates that the predominant aerosol type in spring is dust. The results point out that the October "black cloud" events in the Nile region contain both dust and carbonaceous aerosols; however the governing aerosol type is smoke. We can conclude that the high aerosol concentrations in October, during the "black cloud" are attributed primarily to biomass burning which is enhanced by emissions from vehicular, industrial, and secondary aerosols. Generally, aerosols coming from biomass burning consist of particles that are very light absorbing and contain significant amounts of black and organic carbon (Torres et al., 1998). Analyses of the black carbon (BC) concentrations, monitored in Cairo during autumn 2004 and spring 2005, indicates that vehicle traffic is the major source of $\mathrm{BC}$ in Cairo during the daytime (Mahmoud et al., 2008). The hourly concentrations are significantly larger in fall than in spring, where biomass burning emissions amplify the BC levels (Mahmoud et al., 2008). The elevated $B C$ concentrations during fall may be responsible for high absorbing aerosols at this time.

The biomass burning emissions of rice straw generate smoke particles which mix with the local pollution aerosols, producing various size fractions and almost spherical particles. These findings expand upon the previous results obtained of Marey et al. (2010). Since Cairo and the Nile Delta lie between the Western and the Arabian deserts, it is not surprising that their air qualities are affected by dust during the whole year, with peaks during strong spring wind events (Zakey et al., 2004). While dust aerosols contribute to enhancements the air pollution levels in fall (Favez et al., 2008; Prasad et al., 2010). We argue that the main contributing factor to the black cloud pollution is the biomass burning of agricultural waste during the fall season. Our climatological results may provide a new approach to investigate the impact of air pollution episodes on regional climate systems. 
Acknowledgements. The authors thank the MOPITT project for supporting this research. Many thanks are extended to Steven T. Massie and Omar Torres for their valuable comments and suggestions. We also would like to thank the Principal Investigators and their staff of the AERONET Cairo site, for providing their valuable data. We gratefully acknowledge the NASA Langley Research Center LaRC data center for providing the OMI, MODIS, CALIPSO and MISR data. Finally, the authors acknowledge the NOAA Air Resources Laboratory (ARL) for providing the meteorology parameters and HYSPLIT model (http://www.arl.noaa.gov/ready.html) which are used in this publication. The National Center for Atmospheric Research is sponsored by the National Science Foundation (NSF). El-Askary would like also to acknowledge the partial support of the NSF grant 0922772 with the Science and Technology for Development Fund (STDF, http://www.stdf.org.eg/) through the US-Egypt joint agreement. Any opinions, findings and conclusions or recommendations expressed in the publication are those of the authors and do not necessarily reflect views of the National Science Foundation.

Edited by: A. Baklanov

\section{References}

Abu-Allaban, M., Gertler, A. W., and Lowenthal, D. H.: A preliminary apportionment of the sources of ambient $\mathrm{PM}_{10}, \mathrm{PM}_{2.5}$, and VOCs in Cairo, Atmos. Environ., 36, 5549-5557, 2002.

Abu-Allaban, M., Lowenthal, D. H., Gertler, A. W., and Labib, M.: Sources of $\mathrm{PM}_{10}$ and $\mathrm{PM}_{2.5}$ in Cairo's ambient air, Environ. Monit. Assess., 133, 417-425, doi:10.1007/s10661-006-9596-8, 2007.

Alfaro, S. C. and Wahab, M. A.: Extreme variability of aerosol optical properties: The Cairo aerosol characterization experiment case study, Nato. Sec. Sci., 2006, 285-299, doi:10.1007/978-14020-5090-9_18, 2006.

Ahmad, S. P., Torres, O., Bhartia, P. K., Leptoukh, G. G., and Kempler, S. J.: Aerosol Index from TOMS and OMI Measurements, 14th Joint Conference on the Applications of Air Pollution Meteorology with the Air and Waste Management Association, 2006.

Barnaba, F. and Gobbi, G. P.: Aerosol seasonal variability over the Mediterranean region and relative impact of maritime, continental and Saharan dust particles over the basin from MODIS data in the year 2001, Atmos. Chem. Phys., 4, 2367-2391, doi:10.5194/acp-4-2367-2004, 2004.

Barnes, W. L., Pagano, T. S., Salomonson, V. V., Directorate, E. S., Center, N., and Greenbelt, M. D.: Prelaunch characteristics of the moderate resolution imaging Spectroradiometer (MODIS) on EOS-AM1, IEEE T. Geosci. Remote, 36, 1088-1100, 1998.

Braak, R., de Laat, J., Torres, O., Veihelmann, B., Veefkind, J. P., Kroon, M., and Levelt, P. F.: OMI UV Absorbing Aerosol Index as a Tracer of Australian Biomass Burning Aerosols, Poster: EGU General Assembly, 16-22 April 2007, p. 2997, Vienna, Austria, EGU, 2007.

Borai, E. H. and Soliman, A. A.: Monitoring and statistical evaluation of heavy metals in airborne particulates in Cairo, Egypt, J. Chromatogr. A, 920, 261-269, 2001.

Bull, M., Matthews, J., McDonald, D., Moroney, C., Paradise, S., and Smyth, M.: MISR Data Products Specifications, JPL, available at: http://eosweb.larc.nasa.gov/PRODOCS/misr/DPS/ DPS_v43_RevQ.pdf, 2008.

Dey, S. and Di Girolamo, L.: A climatology of aerosol optical and microphysical properties over the Indian subcontinent from 9 years (2000-2008) of Multiangle Imaging Spectroradiometer (MISR) data, J. Geophys. Res., 115, D15204, doi:10.1029/2009JD013395, 2010.

Diner, D. J., Beckert, J. C., Reilly, T. H., Bruegge, C. J., Conel, J. E., Kahn, R. A., Martonchik, R. A., Ackerman, T. P., Davies, R., Gerstl, S., Gordon, H. R., Muller, J.-P., Myneni, R., Sellers, P., Pinty, B., and Verstraete, M.: Multi-angle Imaging Spectro Radiometer (MISR) instrument description and experiment overview, IEEE T. Geosci. Remote, 36, 1072-1087, 1998.

Diner, D. J., Abdou, W. A., Bruegge, C. J., Conel, J. E., Crean, K. A., Gaitley, B. J., Helmlinger, M. C., Kahn, R. A., Martonchik, J. V., Pilorz, S. H., and Holben, B. N.: MISR aerosol optical depth retrievals over southern Africa during the SAFARI-2000 dry season campaign, Geophys. Res. Lett., 28, 3127-3130, 2001.

Diner, D. J., Abdou, W., Ackerman, T., Crean, K., Gordon, H., Kahn, R., Martonchik, J., McMuldroch, S., Paradise, S., Pinty, B., Verstrete, M., Wang, M., and West, R.: MISR Level 2 Aerosol Retrieval Algorithm Theoretical Basis, JPL, D11400, available at: http://eospso.gsfc.nasa.gov/ eos_homepage/for_scientists/atbd/docs/MISR/atbd-misr-09.pdf, 2008.

Draxler, R. R. and Hess, G. D.: Description of the HYSPLIT 4 modeling system, NOAA Tech. Memo., ERL ARL-224, 24, 1997.

Draxler, R., Draxler, R., Stunder, B., Rolph, G., Stein, A., and Taylor, A.: HYSPLIT4 User's Guide version 4.9, available at: http://www.arl.noaa.gov/documents/reports/hysplit_ user_guide.pdf, 2009.

Dubovik, O. and King, M. D.: A flexible inversion algorithm for retrieval of aerosol optical properties from Sun and sky radiance measurements, J. Geophys. Res., 105, 673-20, 2000.

DWUA (Demographia World Urban Areas) \& Population Projections: 7th Comprehensive Edition (Revised April 2011), available at: http://www.demographia.com/db-worldua.pdf, 2011.

El-Askary, H. and Kafatos, M.: Dust storm and black cloud influence on aerosol optical properties over Cairo and the greater delta region, Egypt, Int. J. Remote Sens., 29, 7199-7211, 2008.

El-Askary, H., Farouk, R., Ichoku, C., and Kafatos, M.: Transport of dust and anthropogenic aerosols across Alexandria, Egypt, Annales Geophysicae, 27, 2869-2879, 2009.

El-Metwally, M., Alfaro, S. C., Abdel Wahab, M., and Chatenet, B.: Aerosol characteristics over urban Cairo: Seasonal variations as retrieved from Sunphotomete measurements, J. Geophys. Res., 113, D14219, doi:10.1029/2008JD009834, 2008.

El-Metwally, M., Alfaro, S. C., Abdel Wahab, M. M., Zakey, A. S., and Chatenet, B.: Seasonal and inter-annual variability of the aerosol content in Cairo (Egypt) as deduced from the comparison of MODIS aerosol retrievals with direct AERONET measurements, Atmos. Res., 97, 14-25, 2010.

El-Metwally, M., Alfaro, S. C., Abdel Wahab, M. M., Favez, O., Mohamed, Z., and Chatenet, B.: Aerosol properties and associated radiative effects over Cairo (Egypt), Atmos. Res., 9, 263276, 2011.

Favez, O., Cachier, H., Sciare, J., Alfaro, S. C., El-Araby, T. M., Harhash, M. A., and Abdelwahab, M. M.: Seasonality of major aerosol species and their transformations in Cairo megacity, 
Atmos. Environ., 42, 1503-1516, 2008.

Fleishman, J.: EGYPT Cairo's hovering "black cloud", available at: http://latimesblogs.latimes.com/babylonbeyond/2009/10/firesburn-in-the-provinces-and-mornings-break-smoky-inthe-cityits-harvest-time-the-rice-has-been-gathered-andfarmers.html, 2009.

Haywood, J. M., Ramaswamy, V., and Soden, B. J.: Tropospheric Aerosol climate forcing in clear-sky satellite observations over the oceans, Science, 283, 1299-1303, doi:10.1126/science.283.5406.1299, 1999.

Heinrich, J. and Slama, R.: Fine particles, a major threat to children, Int. J. Hyg. Envir. Heal., 210, 617-622, 2007.

Herman, J. R. and Celarier, E.: Earth's surface reflectivity climatology at 340-380 nm from TOMS data, J. Geophys. Res., 102, 3-28, doi:10.1029/97JD02074, 1997.

Holben, B. N., Slutsker, I., Tanré, D., Buis, J. P., Setzer, A., Vermote, E., Reagan, J. A. Y., Kaufman, J., Nakajima, T., Lavenu, F., Jankowiak, I., and Smirnov, A.: AERONET - A federated instrument network and data archive for aerosol characterization, Remote Sens. Environ., 66, 1-16, 1998.

Horvath, H., Alados Arboledas, L., Olmo, F. J., Jovanoviæ, O., Gangl, M., Kaller, W., Sánchez, C., Sauerzopf, H., and Seidl, S.: Optical characteristics of the aerosol in Spain and Austria and its effect on radiative forcing, J. Geophys. Res., 107, 4386, doi:10.1029/2001JD001472, 2002.

Hossny, E., Mokhtar, G., El-Awady, M., Ali, I., Morsy, M., and Dawood, A.: Environmental exposure of the pediatric age groups in Cairo city and its suburbs to cadmium pollution, Sci. Total Environ., 273 , 135-146, 2001.

Hsu, N. C., Tsay, S. C., King, M. D., and Herman, J. R.: Aerosol properties over bright-reflecting source regions, IEEE T. Geosci. Remote, 42, 557-569, doi:10.1109/TGRS.2004.824067, 2004.

Hsu, N. C., Tsay, S., King, M. D., and Herman, J. R.: Deep Blue Retrievals of Asian Aerosol Properties During ACE-Asia, IEEE T. Geosci. Remote, 44, 3180-3195, ISSN 0196-2892 CODEN IGRSD2., 2006.

Kaufman, Y. J., Tanré, D., Remer, L. A., Vermote, E. F., Chu, A., Holben, B. N.: Operational remote sensing of tropospheric aerosol over land from EOS moderate resolution imaging spectroradiometer, J. Geophys. Res., 102, 17-51, 1997a.

Kaufman, Y. J., Wald, A. E., Remer, L. A., Gao, B.-C., Li, R.R., and Flynn, L.: The MODIS 2.1-mm channel-correlation with visible reflectance for use in remote sensing of aerosol, IEEE T. Geosci. Remote, 355, 1286-1298, doi:10.1109/36.628795, 1997b.

Kistler, R., Kalnay, E., Collins, W., Saha, S., White, G., Woollen, J., Chelliah, M., Ebisuzaki, W., Kanamitsu, M., Kousky, V., Dool, H., Jenne, R.: The NCEP-NCAR 50year reanalysis: Monthly means CD-ROM and documentation, B. Am. Meteorol. Soc., 82, 247-267, doi:10.1175/15200477(2001)082;0247:TNNYRM;2.3.CO;2, 2001.

Labonne, M., Brếon, F.-M., and Chevallier, F.: Injection height of biomass burning aerosols as seen from a spaceborne lidar, Geophys. Res. Lett., 34, L11806, doi:10.1029/2007GL029311, 2007.

Liu, Z., Vaughan, M. A., Winker, D. M., Hostetler, C. A., Poole, L. R., Hlavka, D., Hart, W., and McGill, M.: Use of probability distribution functions for discriminating between cloud and aerosol in lidar backscatter data, J. Geophys. Res., 109, D15202, doi:10.1029/2004JD004732, 2004.
Mahowald, N. M. and Dufresne, J.-L.: Sensitivity of TOMS aerosol index to boundary layer height: Implications for detection of mineral aerosol sources, Geophys. Res. Lett., 31, L03103, doi:10.1029/2003GL018865, 2004.

Mahmoud, K. F., Alfaro, S. C., Favez, O., Abdel Wahab, M. M.: Origin of black carbon concentration peaks in Cairo (Egypt), Atmos. Res., 89, 161-169, 2008.

Marey, H. S., Gille, J. C., El-Askary, H. M., Shalaby, E. A., and ElRaey, M. E.: Study of the formation of the "black cloud" and its dynamics over Cairo, Egypt, using MODIS and MISR sensors, J. Geophys. Res., 115, D21206, doi:10.1029/2010JD014384, 2010.

Martonchik, J. V., Diner, D. J., Crean, K. A., and Bull, M. A.: Regional aerosol retrieval results from MISR, IEEE T. Geosci. Remote, 40, 1520-1531, 2002.

Martonchik, J. V., Diner, D. J., Kahn, R., Gaitley, B., and Holben, B. N.: Comparison of MISR and AERONET aerosol optical depths over desert sites, Geophys. Res. Lett., 31, L16102, doi:10.1029/2004GL019807, 2004.

McGill, M. J., Vaughan, M. A., Trepte, C. R., Hart, W. D., Hlavka, D. L., Winker, D. M., and Kuehn, R.: Airborne validation of spatial properties measured by the CALIPSO lidar, J. Geophys. Res., 112, D20201, doi:10.1029/2007JD008768, 2007.

Meloni, D., di Sarra, A., di Iorio, T., and Fiocco, G.: Influence of the vertical profile of Saharan dust on the visible direct radiative forcing, J. Quant. Spectrosc. Ra., 93, 347-413, 2005.

Moorthy, K. K., Nair, V. S., Babu, S. S., and Satheesh, S. K.: Spatial and vertical heterogeneities in aerosol properties over oceanic regions around India: Implications for radiative forcing, Q. J. Roy. Meteor. Soc., 135, 2131-2145, doi:10.1002/qj.525, 2009.

Moroney, C., Davies, R., and Muller, J.-P.: Operational retrieval of cloud-top heights using MISR data, IEEE T. Geosci. Remote, 40, 1532-1540, 2002.

Moulin, C., Lambert, C. E., Dayan, U., Masson, V., Ramonet, M., Bousquet, P., Legrand, M., Balkanski, Y. J., Guelle, W., Marticorena, B., Bergametti, G., and Dula, F.: Satellite climatology of African dust transport in the Mediterranean atmosphere, J. Geophys. Res., 103, 13137-13144, doi:10.1029/98JD00171, 1998.

Muller, J., Mandanayake, A., Moroney, C., Davies, R., Diner, D. J., and Paradise, S.: MISR stereoscopic image matchers: Techniques and results, IEEE T. Geosci. Remote, 40, 1547-1559, 2002.

Nasralla, M. M.: Air pollution in greater Cairo, In: Proceeding of the Italian-Egyptian Study-days on the Environment, Proceeding of the Italian-Egyptian Study-days on the Environment, Cairo, Egypt, 88-100, 1994.

Papadimas, C. D., Hatzianastassiou, N., Mihalopoulos, N., Querol, X., and Vardavas, I.: Spatial and temporal variability in aerosol properties over the Mediterranean basin based on 6year (2000-2006) MODIS data, J. Geophys. Res., 113, D11205, doi:10.1029/2007JD009189, 2008.

Prasad, A. K., El-Askary, H., and Kafatos, M.: Implications of high altitude desert dust transport from Western Sahara to Nile Delta during biomass burning season, Environ. Pollut., 158, 33853391, 2010.

Remer, L. A., Kaufman, Y. J., Tanré, D., Mattoo, S., Chu, D. A., Martins, J. V., Li, R. R., Ichoku, C., Levy, R. C., Kleidman, R. G., Eck, T. F., Vermote, E., and Holben, B. N.: The MODIS aerosol algorithm, products, and validation, J. Atmos. Sci., 62, 947-973, 2005. 
Remer, L. A., Tanré, D., Kaufman, Y. J., Levy, R., and Mattoo, S.: Algorithm for remote sensing of tropospheric aerosols from MODIS, Collection 5, Product ID: MOD04/MYD04, last updated 11/01/2006, available at: http://modis.gsfc.nasa.gov/data/ atbd/atbd_mod02.pdf, 2006.

Remer, L. A., Kleidman, R. G., Levy, R. C., Kaufman, Y. J., Tanré, D., Mattoo, S., Martins, J. V., Ichoku, C., Koren, I., Yu, H., and Holben, B. N.: Global aerosol climatology from the MODIS satellite sensors, J. Geophys. Res., 113, D14S07, doi:10.1029/2007JD009661, 2008.

Rosenfeld, D.: Suppression of rain and snow by urban and industrial air pollution, Science, 287, 1793-1796, 2000.

Robaa, S. M.: A study of ultraviolet solar radiation at Cairo urban area, Egypt, Sol. Energy, 77, 251-259, 2004.

Salomonson, V. V., Barnes, W. L., Maymon, P. W., Montgomery, H. E., and Ostrow, H.: MODIS: advanced facility instrument for studies of the Earth as a system, IEEE T. Geosci. Remote, 27, $145-153,1989$.

Stammes, P. and Noordhoek, R.: OMI Algorithm Theoretical Basis Document Volume III: Clouds, Aerosols, and Surface UV Irradiance, Tech. Rep. ATBD-OMI-03, Version 2.0, 2002.

Stephens, G., Vane, D. G., Boain, R. J., Mace, G. G., Sassen, K., Wang, Z., Illingworth, A. J., O'Connor, E. J., Rossow, W. B., Durden, S. L., Miller, S. D., Austin, R. T., Benedetti, A., and Mitrescu, C.: The CloudSat mission and the A-train, B. Am. Meteorol. Soc., 83, 1771-1790, 2002.

Tanré, D., Kaufman, Y. J., Herman, M., and Mattoo, S.: Remote sensing of aerosol properties over oceans using the MODIS/EOS spectral radiances, J. Geophys. Res., 102, 1697116988, doi:10.1029/96JD03437, 1997.
Torres, O., Bhartia, P. K., Herman, J. R., Ahmad, Z., and Gleason, J.: Derivation of aerosol properties from satellite measurements of backscattered ultraviolet radiation: theoretical basis, J. Geophys. Res., 103, 17099-17110, 1998.

Torres, O., Bhartia, P. K., Sinyuk, A., Welton, E. J., and Holben, B.: Total Ozone Mapping Spectrometer measurements of aerosol absorption from space: Comparison to SAFARI 2000 ground-based observations, J. Geophys. Res., 110, D10S18, doi:10.1029/2004JD004611, 2005.

Torres, O., Tanskanen, A., Veihelmann, B., Ahn, C., Braak, R., Bhartia, P. K., Veefkind, P., and Levelt, P.: Aerosols and surface UV products from Ozone Monitoring Instrument observations: An overview, J. Geophys. Res., 112, D24S47, doi:10.1029/2007JD008809, 2007.

Winker, D. M., Pelon, J., and McCormick, M. P.: The CALIPSO mission: Spaceborne lidar for observation of aerosols and clouds, Proc. SPIE, 4893, 1-11, 2003.

Winker, D. M., Hunt, W. H., and Hostetler, C. A.: Status and performance of the CALIOP lidar, Proc. SPIE-Int. Soc. Opt. Eng., $5575,8-15,2004$.

Winker, D. M., Hostetler, C. A., Vaughan, M. A., and Omar, A. H.: CALIOP Algorithm Theoretical Basis Document, Part 1: CALIOP Instrument, and Algorithms Overview, available at: http://www-calipso.larc.nasa.gov/resources/pdfs/ PC-SCI-202.Part1_v2-Overview.pdf, 2006.

Zakey, A. S., Abdelwahab, M. M., and Makar, P. A.: Atmospheric turbidity over Egypt, Atmos. Environ., 38, 1579-1591, 2004. 